\title{
MULHERES EMPREENDEDORAS: DEMANDAS E CONFLITOS NO SETOR DE EDUCAÇÃO INFANTIL
}

Ananda Silveira Bacelar ${ }^{1}$

Almiralva Ferraz Gomes ${ }^{2}$

Weslei Gusmão Piau Santana ${ }^{2}$

Rita De Cássia Oliveira Lima Alves ${ }^{2}$

\footnotetext{
${ }^{1}$ Universidade Estadual do Sudoeste da Bahia

${ }^{2}$ Universidade Estadual do Sudoeste da Bahia/Departamento de Ciências Sociais Aplicadas (DCSA)
} 


\section{MULHERES EMPREENDEDORAS: DEMANDAS E CONFLITOS NO SETOR DE EDUCAÇÃO INFANTIL}

Resumo: A participação feminina no mercado de trabalho, ainda em processo de estruturação, conduz a mudanças nas esferas econômica, social, cultural e comportamental. Nesse contexto, buscou-se no estudo, a análise da relação entre trabalho e família para empreendedoras do segmento de educação infantil de Vitória da Conquista - BA, de modo a questionar a visão essencialista de gênero, que polariza condutas femininas e masculinas. $\mathrm{O}$ estudo consiste em uma análise qualitativa a partir da entrevista de dez empreendedoras e é considerado um estudo de caso com múltiplas unidades de análise. Dentre os achados da pesquisa, as falas das entrevistadas demonstram a construção social de gênero e caracterizam o perfil intuitivo e sensível das empreendedoras, motivado pela autorrealização e crescimento pessoal. Dentre as principais dificuldades relacionadas ao cotidiano feminino, a multiplicidade de papeis, o estresse causado pela conciliação de demandas e a falta de tempo para realizar atividades foram as relatadas pelas empreendedoras.

Palavras-chave: Empreendedora. Família. Gênero. Trabalho.

\section{Introdução}

A participação feminina no mercado de trabalho, embora ainda em processo de estruturação, conduz a mudanças nas esferas econômica, social, cultural e comportamental. A necessidade de se compreender como esse fenômeno atual e suas possíveis implicações demanda a realização de estudos que abarquem as discussões sobre relações de gênero e trabalho, os quais perpassam, ainda, na articulação entre dois eixos norteadores da vida cotidiana: trabalho e família. Neste contexto, a carreira profissional, conjugada à responsabilidade familiar, representa na contemporaneidade a divisão de atribuições entre homens e mulheres, pois, embora a mulher tenha ocupado funções na esfera pública, há ainda o compromisso em subsidiar o trabalho doméstico, representado pela esfera privada. Convém, assim, analisar os conflitos, os impactos sociais e individuais e as formas de adequação ao fenômeno de conciliação entre as duas demandas.

Homens e mulheres são doutrinados, desde a infância, a ocupar posições sociais em áreas determinadas femininas ou masculinas, a exemplo do encargo feminino de cuidar da casa e família. Para Sorj (2013), a noção de esferas separadas procurou ser, ao mesmo tempo, uma interpretação da sociedade e uma prescrição moral sobre a divisão sexual do trabalho desejável. Nesse contexto, a escolha do segmento de educação infantil baseia-se no pressuposto de que as mulheres tendem a atuar em áreas relacionadas ao cuidado.

A proposta de que há diferenças natas no comportamento e desenvolvimento de habilidades pressupõe uma definição de papeis que limita a ascensão feminina no mercado de trabalho. Para Pereira et al. (2014), a socialização direcionada à vida profissional em
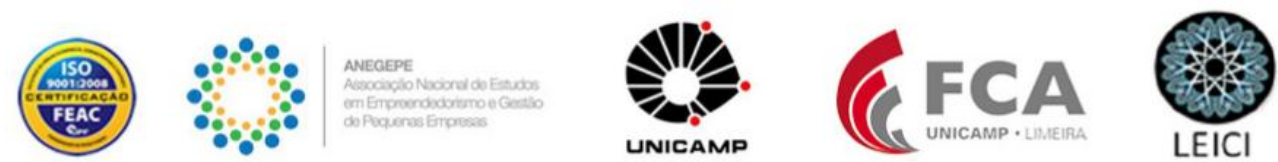
detrimento da vida familiar e doméstica representa uma condição feminina que define a posição hierárquica na empresa, o salário e o reconhecimento, pois, considerando os dois âmbitos (público e privado), há um trade-off que pressupõe maior dedicação a determinada atividade enquanto se despende menor tempo e esforços na outra.

Diante do exposto, o presente artigo propõe-se a compreender de que modo as empreendedoras atuam como gestoras e conciliam demandas, no segmento de educação infantil, em Vitória da Conquista. Para tanto, dispõe-se de um referencial teórico que aborda o empreendedorismo feminino e as relações entre trabalho e família, dos procedimentos metodológicos, de uma breve contextualização do estudo e análise das falas das empreendedoras e, por fim, as considerações finais da pesquisa.

\section{Referencial Teórico}

A inserção feminina no mercado de trabalho abrange a participação das mulheres no empreendedorismo brasileiro. Segundo dados do GEM (2016), elas já correspondem a 51\% dos empreendedores iniciais, muito embora as empresas geridas por mulheres tendem a ser menos duradouras, devido às maiores dificuldades que apresentam ao optar por empreender. Quanto à escolha do ramo a ser seguido, segundo o SEBRAE (2014), as mulheres tendem a buscar áreas não dominadas pelo universo masculino, tais como: comércio (50\%) e serviços (35\%), enquanto apenas $7 \%$ residem na indústria e $8 \%$ em outros setores.O perfil dos empreendedores iniciais brasileiros é predominantemente composto por mulheres entre 25 e 34 anos, que possuem renda familiar de dois salários mínimos, casadas, de pele parda e ensino médio completo ou ensino superior incompleto (GEM 2016). A intensa presença feminina na criação de negócios confirma a relevância econômica que o empreendedorismo feminino tem apresentado.

Na concepção de Ferreira e Nogueira (2013), o empreendedorismo se insere na vida dos indivíduos, de modo a estabelecer uma relação intrínseca com suas vidas. Entender o empreendedorismo como um ato inerente à vida pessoal e em sociedade implica na busca pela convergência de interesses pessoais (relacionados ao negócio e às demandas domésticas), necessidades do coletivo e projeções dos anseios do mercado. No entanto, a concepção do empreendedor como um sujeito capitalista, provedor dos bens de consumo e métodos de produção com função principal em identificar oportunidades e transformá-las em valores econômicos, negligencia "[...] as implicações para as relações de trabalho contemporâneas da (re)produção da ideia de empreendedorismo" (COSTA; BARROS; CARVALHO, 2011, p. 183). Essa premissa neutraliza a ideia de que o empreendedor é, primeiramente, uma figura econômica e autônoma, inserida no mundo competitivo dos negócios.

Nessa perspectiva, Bernardi (2012) apresenta duas vertentes do comportamento empresarial, que consideram diferentes visões da gestão: comportamento competitivo e sistêmico/holístico. O modelo de postura competitiva valoriza a geração de lucros e, portanto, considera que a racionalidade e a saúde da empresa se relacionam ao desempenho no mercado, ao destacar como principal objetivo a maximização dos lucros, de modo a representar o contexto dos negócios de modo simplificado e linear. Em contraposto, a postura sistêmica ou holística considera a visão global da empresa como pertencente de um todo complexo e inter-relacionado e, por isso, exige do gestor um senso maior de flexibilidade,

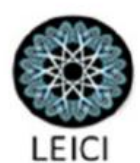


agilidade e adaptabilidade, considerando que a mudança é inerente ao sistema e os riscos pertencem, naturalmente, à realidade empresarial.

Ante o exposto, é possível observar que empreendedorismo em si exige dos indivíduos uma percepção de mudança e atenção ao ambiente circundante. Em sua perspectiva tecnicista, Filion (2000) aponta para a necessidade de se adotar um sistema de vida ecológico, em que devem ser ponderados os esforços pessoais e o quanto será exigido de empenho das pessoas envolvidas no projeto. Tal premissa considera que os indivíduos devem buscar o equilíbrio, isto é, dedicar-se ao empreendimento e usufruir dos prazeres da vida pessoal. Essa concepção é facilmente aplicável à ideia de dupla responsabilidade feminina, em que as mulheres buscam realização profissional sem que haja prejuízos na esfera particular.

A noção de empreendedorismo como um exercício em que se exige proatividade desloca a discussão da caracterização estereotipada do perfil empreendedor para o desenvolvimento de competências para gerir um negócio que culmina na efetiva ação empreendedora. Nesse sentido, faz-se necessário o desenvolvimento da visão empreendedora, isto é, do conjunto de ideias e objetivos que nortearão a consolidação do empreendimento. Para tanto, destacam-se três vertentes do processo de construção visionária do empreendedor: emergência, centralização e complementação, propostas por Filion (1993). A visão emergente consiste nas ideias primárias sobre o negócio, em que a projeção do empreendimento ainda é pouco clara. A visão central representa a evolução das emergentes, considerando que há conhecimento dos fatores influenciadores do negócio, bem como das necessidades do mercado. Por fim, as visões complementares relacionam-se com os aspectos gerenciais, que incluem ajustes e melhorias para alcançar um desempenho mais satisfatório.

Para Martins et al. (2010), as mulheres desenvolveram significações em relação aos padrões essencialistas de modelos empreendedores, ou seja, consideram um desafio no mercado de trabalho a reafirmação de atributos femininos paralelamente à absorção de elementos caracterizados como masculinos, a fim de obter o sucesso profissional. Dentre as características ditas naturalmente femininas, destacam-se, para Alves et al. (2016), facilidade no trabalho em equipe, dedicação, sensibilidade, detalhismo, pró-atividade, persistência, disciplina, capacidade de controlar e amenizar conflitos e mentalidade flexível. Simultaneamente, para Martins et al. (2010), as mulheres apresentam tendência à organização, extroversão e autoconfiança, são capazes de lidar com situações inesperadas, possuem habilidades comunicativas e são autoconfiantes. Muito embora tais particularidades sejam valorizadas na gestão de empresas para assumirem cargos de gestão, frequentemente, as mulheres recorrem à adoção de características socialmente masculinizadas para reforçar uma imagem de força, seriedade, racionalidade e utilitarismo (MACEDO et al., 2012).

O estudo do comportamento feminino ao empreender apresenta, então, duas vertentes antagônicas: (1) a adequação à postura masculina, de modo a assumir principalmente a racionalidade tradicionalmente atrelada ao homem ou (2) a definição de uma conduta que valoriza ainda mais as características supostamente femininas. Considera-se que há uma hegemonia masculina no que tange as características tidas como adequadas para se ocupar cargos de gerência e coordenação. Assim, por um lado, as mulheres que almejam determinada função tendem a se masculinizar de modo a não haver descaracterização das bases sociais de dominação masculina. Tal fator considera o espaço das mulheres nas organizações como uma representação simbólica e não figura mudança nas estruturas das organizações e nas práticas

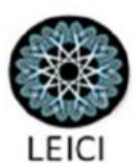


sociais (SALES et al., 2013). Por outro, os valores socialmente femininos são buscados pelas empresas, a exemplo do relacionamento interpessoal, cooperação em detrimento da competição e o uso da motivação no lugar do controle (GOMES, 2004). No entanto,

[...] os estilos de gestão considerados 'femininos' se encontram presentes, também, em homens empreendedores e vice-versa. Assim, a condição de homem ou mulher explica pouco a prática empreendedora, sendo necessário aprumar o foco em direção à questão de gênero (MELLO; CORDEIRO, 2010, p. 285, grifo do autor).

Portanto, há a necessidade de supressão do discurso de superioridade ou submissão de gênero em prol da valorização de um modelo de gestão compartilhada por características socialmente femininas e masculinas. Para Gomes (2004), a forma de gestão feminina não pode ser considerada superior ou substituta da gestão masculina ou vice-versa. Ambos os modelos devem ser vistos como complementares entre si.

Para compreender a ação empreendedora feminina no mercado de trabalho, convém analisar os fatores que levam as mulheres a empreender, tais como: realização pessoal, independência (PELOGIO et al., 2011), ascensão financeira e desenvolvimento de potencial (MACHADO; GAZOLA; ANEZ, 2013). Em suma, para Jonathan (2005), a satisfação das mulheres ao empreender provém da possibilidade de reconhecimento por realizações, autoridade na tomada de decisões, desenvolvimento de ideias e competências e a autoafirmação de suas ideias, que o ambiente de negócio proporciona.

Paralelamente, os obstáculos que elas encontram ao gerir seus negócios residem no conflito entre demandas familiares e profissionais, no preconceito (ALPERSTEDT; FERREIRA; SERAFIM, 2014), na falta de credibilidade, na multiplicidade de papeis e nos impactos na qualidade de vida (MACHADO, 2012). Tais fatores indicam uma percepção do constructo que o empreendedorismo representa para as mulheres, de modo que as dificuldades demonstram a subjugação das mulheres em relação aos homens. Conforme explicita Jonathan (2005), ao mesmo tempo em que favorece o crescimento pessoal, o trabalho das empreendedoras gera desafios que as induzem a desenvolver habilidades.

Ao considerar as influências que as relações de gênero e as socializações exercem sobre as decisões empreendedoras das mulheres, torna-se pertinente discutir as questões que permeiam o empreendedorismo feminino nesse contexto. A família é considerada o sistema básico de relações que moldará a visão inicial e as visões complementares do negócio serão influenciadas pelas relações que se estabelecem em contato com a sociedade. Para Strobino e Teixeira (2014), há uma tendência de mulheres que pertencem a famílias de empreendedores serem direcionadas a gerirem o próprio negócio. Portanto, a ação empreendedora é fortemente influenciada pelas projeções sociais e familiares que as mulheres subjetivam no decorrer de suas formações.

Na visão de Filion (1999), a disposição do empreendedor em trabalhar com determinado setor empresarial baseia-se em três níveis de relações. Desse modo, o indivíduo jovem no começo da criação de uma empresa tende a sofrer maior influência da família, isto é, das relações primárias. Para Berger e Luckmann (2010), a socialização primária vai além do aprendizado cognoscitivo e está relacionada também a circunstâncias emocionais, que influenciam significações dos indivíduos. Sendo assim, a criança absorve papéis e atitudes por meio da identificação com os significativos que tem contato durante a infância e, por isso,
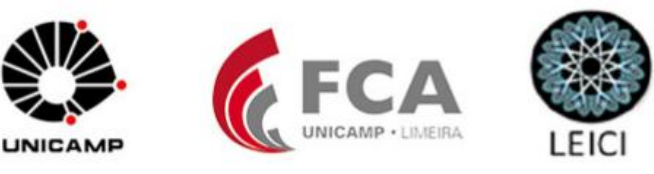
torna-se capaz de identificar a si mesma (BERGER; LUCKMANN, 2010). Convém ressaltar que esse processo de significação dos elementos familiares pode conduzir o indivíduo a empreender, principalmente se for identificado pela criança uma referência de figura empreendedora.

A dificuldade de conciliar as demandas pessoais e profissionais, a preocupação excessiva com o tempo, a necessidade de flexibilização, a ausência de suporte, dentre outras, é uma realidade cotidiana feminina. Nessa vertente, há a busca pelo equilíbrio entre trabalho e vida familiar (GUIMARÃES; PETEAN; SOUZA, 2012), visto que para Cyrino (2009), a desigualdade de responsabilidades com a esfera doméstica não é harmoniosa e pode gerar conflitos. Em especial, as mulheres necessitam de uma nova organização, pois a dupla jornada de trabalho ou o trabalho redobrado gera uma sobrecarga psíquica e laboral. Uma análise sobre os tempos de trabalho de homens e mulheres, a partir dos indicadores da Pesquisa Nacional por Amostra de Domicílios (Pnad), proposta por Dedecca, Ribeiro e Ishii (2009), revela que, segundo dados de 2006, o total de horas de trabalho em quaisquer das ocupações, era de 49 para homens e 56 para mulheres. Vale ressaltar que a composição da jornada é que, de fato, diferencia as rotinas laborais entre os sexos, posto que, das 49 masculinas, apenas cinco eram destinadas à reprodução social e 44 eram dedicadas à carreira profissional, enquanto as mulheres despendem 19 horas na dinâmica doméstica e 37 no mercado de trabalho. Esta discrepância apresenta outras vertentes complementares quando são consideradas as variáveis renda, classe social e raça. Cabe aqui considerar que a pesquisa aponta que as maiores cargas de trabalho na reprodução social estão associadas às mulheres com os mais baixos níveis de escolaridade.

A discrepância entre o volume de horas trabalhadas não somente reafirma as relações de poder como provoca conflitos, a medida que as mulheres buscam a igualdade de funções que está distante da aceitação masculina (JABLONSKI, 2010). Sendo assim, independente do arranjo familiar, numa escala que percorre do mais tradicional ao mais moderno, o conflito nas relações aparece como um aspecto visível e constante no discurso de homens e mulheres (CYRINO, 2009). Uma das novas tendências de arranjos familiares é a adequação das rotinas entre cônjuges: o fenômeno dual career families constata a necessidade de modificação do comportamento de homens e mulheres em relação ao cuidado e atenção à esfera doméstica. "Pai e mãe assumem, conjuntamente, o papel de protagonistas para sustento do lar, ou seja, funções até então distribuídas e praticadas segundo o gênero reconfiguram-se, moldando um novo cenário" (SANTOS; CASADO, 2011, p. 4). Esse modelo exemplifica a coexistência de duas carreiras teoricamente igualitárias, que aponta para uma gradativa reestruturação do papel feminino na sociedade, no mercado de trabalho e na esfera privada.

Para Tomaz (2015), na contemporaneidade, a maternidade se sobrepõe à perspectiva biológica e universal e atua como constituinte da figura feminina. Segundo Silveira e Hanashiro (2011), a centralidade da maternidade para a autodefinição das mulheres tem a forma de um mandato de tal modo que, quando escolhem não ter filhos, vão de encontro às forças sociais e culturais. A abdicação da maternidade ou a secundarização da ideia promove à mulher a possibilidade de seguir livremente sua carreira profissional e ainda concorrer com mais chances no mercado de trabalho, visto que no Brasil, há uma resistência na contratação de mulheres, que se agrava quando se trata de mães em potencial.
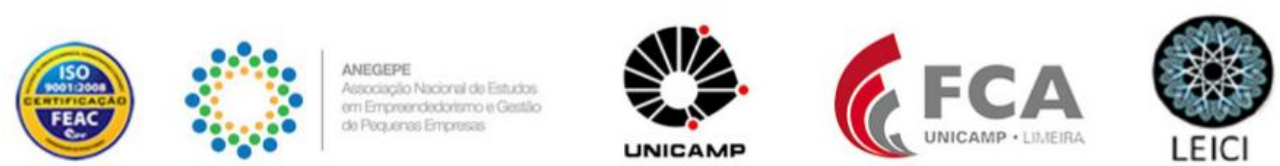
Diante de tantas demandas, a condição da maternidade atrelada ao cuidado da casa e à carreira profissional, gera para a mulher um estado de sobrecarga emocional e física. Por conta desse processo de responsabilização excessiva, há uma tendência feminina em delegar funções e recorrer à terceirização das atividades, fenômeno que, de acordo com Sorj (2013), representa a desintegração da ordem tradicional de gênero das sociedades contemporâneas seguida pela desfamilização do cuidado. A tendência é de que haja uma divisão dos afazeres domésticos entre os cônjuges e o uso de artifícios externos, para suprir a ausência de ambos na esfera doméstica.

A existência de estruturas de apoio para o cuidado das crianças apresenta duas vertentes: a primeira relaciona a creche ou a educação infantil primária como um elemento crucial para o desenvolvimento da vida profissional feminina de modo saudável, visto que a preocupação das mulheres reside em encontrar um lugar seguro e adequado para deixarem os filhos (GUIMARÃES; PETEAN; SOUZA, 2012). A segunda retoma a discussão do care como uma característica inata das mulheres, à medida que elas se sentem mais confortáveis e despreocupadas em confiar o cuidado das crianças a outras mulheres, na estrutura formal da educação infantil ou com familiares/babás.

\section{Procedimentos Metodológicos}

O estudo apresenta natureza teórico-empírica, visto que possui elementos que podem ser mensurados facilmente, a partir da pesquisa de campo, enquanto outros necessitam de um embasamento teórico mais complexo. Para Gil (2002), as variáveis presentes nos levantamentos sociais são facilmente observáveis e mensuráveis, enquanto outros fenômenos mais subjetivos são difíceis de serem interpretados e transformados em informações conclusivas, sendo necessária a definição teórica, a fim de torná-los passíveis de observação empírica e mensuração.

Quanto ao tipo de pesquisa, para atingir o objetivo proposto, o presente estudo caracteriza-se como descritivo e exploratório. Segundo Fontelles et al. (2009, p. 6), a pesquisa descritiva "[...] visa apenas observar, registrar e descrever as características de um determinado fenômeno ocorrido em uma amostra ou população, sem, no entanto, analisar o mérito de seu conteúdo". Enquanto a pesquisa exploratória considera uma aproximação do pesquisador com o tema, a fim de permitir maior familiarização com os fenômenos e fatos que se relacionam ao problema em estudo (FONTELLES et al., 2009).

Referente à estratégia de pesquisa adotada, optou-se pelo estudo de caso com múltiplas unidades de análise. De acordo com Zanella (2011), o estudo de caso é adequado quando o objetivo é estudar exaustivamente um ou poucos objetos de modo a permitir o aprofundamento do conhecimento da realidade de um indivíduo ou grupo de pessoas.

A população do estudo abrange todos os empreendimentos do segmento de educação infantil e creches, da esfera privada, desde que geridos por mulheres, em Vitória da Conquista, região sudoeste da Bahia. Segundo dados do Empresômetro (2017), há em Vitória da Conquista um total de 106 escolas infantis e creches. Para alcançar o objetivo da pesquisa, adotou-se uma amostra não-probabilística, determinada a partir do critério de acessibilidade, que consiste na seleção de elementos de mais fácil acesso que representem, de algum modo, o universo da pesquisa. Esse tipo de amostragem é geralmente utilizado em trabalhos

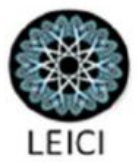


qualitativos e exploratórios, onde a requisição de precisão é relativamente baixa (GIL, 2008). Assim, entrevistaram-se dez empresárias do ramo de educação infantil de Vitória da Conquista - BA.

\section{Empreendedoras da Educação Infantil em Vitória da Conquista}

O segmento de educação infantil de Vitória da Conquista conta com 106 escolas ativas na rede privada, que incluem creches e educação primária, segundo dados do Empresômetro (2017). Foram selecionadas cinco escolas situadas na região leste da cidade, localizadas nos bairros Candeias e Recreio, três no Centro e quatro situadas no oeste, nos bairros Brasil e Jurema. Com a finalidade de preservar a identidade das escolas e das empreendedoras, foram utilizados pseudônimos para ambos.

Os depoimentos das mulheres demonstram que há uma grande parcela de horas diárias dedicadas à gestão, cinco delas dedicam 12 ou mais horas, duas dedicam de 9 a 11 horas, uma dedica de 7 a 9 horas e duas dedicam de 4 a 6 horas. Em contrapartida, cinco mulheres dedicam mais de 8 horas aos cuidados com o lar, três dedicam de 6 a 8 horas e apenas duas dedicam de 3 a 5 horas. Este cenário aponta para uma rotina diária preenchida por responsabilidades domésticas e laborais, que é demonstrada pelas empreendedoras quando solicitadas a falarem a respeito do dia a dia.

[...] Meu dia começa muito cedo, começo ali acordando filho, preparando o café da manhã, organizando tudo isso [...] eu costumo voltar pra casa às 18:30... e a partir desse momento que eu chego em casa aí começam aquelas atividades bem específicas do lar mesmo [...]. (Ivana)

Bem cheio, eu chego na escola por volta de $8 \mathrm{~h}$ saio às $18: 30 \mathrm{~h}$, não vou em casa almoçar [...]. (Lívia)

Ainda referente à rotina, cinco das dez entrevistadas afirmam inevitavelmente levar trabalho para casa. A dedicação e o senso de responsabilidade pelas atividades que são exercidas na escola, ou ainda a baixa disponibilidade de pessoal para cada função, faz com que as mulheres dediquem horas que deveriam ser direcionadas para outras atividades. Segundo Macedo et al. (2012), enquanto os homens enxergam o trabalho como uma forma de atingir objetivos de modo racional e utilitarista, as mulheres se envolvem com o trabalho de modo mais intrínseco, que exige esforço e comprometimento para crescer pessoalmente.

\footnotetext{
Ah escola, escola, trabalho. Passo o dia na escola aí quando eu saio daqui, chego em casa, tomo um banho aí vou bater prova, vou imprimir tarefa, vou fazer um monte de coisa por que tem que levar muita coisa pra lá... por que como a escola é pequena o gestor acaba ocupando muitas funções... (Eliete)

[...] sempre que eu posso, levo muita coisa daqui pra casa também, trabalho em casa pra escola... muitas vezes tiro férias e venho pra cá. [...] trabalho fim de semana, por que como a gente não tem muitos funcionários, a gente tem que assumir muita coisa. Eu to sempre trabalhando... (Vanessa)
} 
A motivação para trabalhar em uma área que as mulheres se identificam contribui para a dedicação excessiva, muitas vezes, em detrimento das demandas pessoais. As entrevistadas divorciadas e solteira revelaram que se dedicam mais à escola do que às suas vidas pessoais. Nesse sentido, considera-se que a dedicação ao ambiente familiar e a responsabilização pelo cuidado da casa é reduzido quando não há marido ou filhos.

É uma carga muito pesada sabe, e assim mudou totalmente hoje o meu foco... o meu foco sempre foi a escola. Eu vivo muito mais a escola do que a minha própria vida. (Patrícia)

Minha casa? Ela que espere (risos) Comida pra filho? Ele que se vire, sabe assim, é... se não der eu não vou almoçar, eu fico aqui, eu emendo... [...] mas ele sabe que a minha prioridade é a escola. (Cláudia)

Rafaela, Ivana, Marina e Lívia, que são casadas, apresentaram um elevado nível de organização e separação das demandas pessoais e profissionais. Muito embora a literatura trate da organização como um atributo feminino e, por isso, as mulheres desempenham melhor funções que envolvam tarefas sutis (OLIVEIRA; BRANGION; MAGALHÃES, 2011), o presente estudo não apresentou resultados conclusivos a respeito da generalização dessa característica como um padrão feminino. Nesse sentido, a organização mostrou-se como um atributo da personalidade do indivíduo, devido às suas vivências e percepções e não como uma predeterminação de que mulheres necessariamente são ou devem ser organizadas.

Sou muito organizada, eu tenho meu tempo de ir ao supermercado, eu tenho meu tempo de estar no trabalho, eu tenho meu tempo de ir no salão, eu tenho tempo de acompanhar meu marido nas coisas que ele faz, gosto de estar junto com ele, tenho tempo de ir na igreja, tenho tempo de orar... eu sou toda organizada nessa questão de tempo, eu não sei como tem gente que fala que não tem tempo pra nada, é só organizar a vida que dá pra tudo. Ou dorme cedo demais ou acorda tarde demais. (Rafaela)

O da escola, estar inteiramente nela enquanto estou aqui e o da família, estar inteiramente na família quando eu estou lá. Mas, inevitavelmente eu preciso levar, o que eu faço é tentar dividir o tempo [...] Eu acho que por mais que não transpareça, as mulheres que exercem uma função no mercado de trabalho e que tenham paralelamente a isso uma vida familiar também, se elas não se pautarem nessa questão da organização, é muito sofrido, fica muito sofrido. (Ivana)

Em contrapartida, Patrícia apresentou como principal dificuldade o saber lidar com o tempo e dedicar-se à escola concomitantemente a outras atividades. A flexibilidade de horários proveniente da atuação como gestora gera a possibilidade de administrar a rotina profissional e pessoal, porém, traz, por vezes, dificuldades para organizar as atividades e responsabilidades de modo a satisfazer as demandas pessoais e domésticas que, muitas vezes, ficam em segundo plano. Lara inclusive demonstra que a falta de tempo é uma das dificuldades que encontra no processo de gestão da escola.

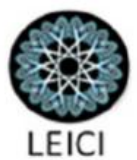


A falta de tempo... hoje eu sou hipertensa e diabética, proveniente de uma vida desregrada nesse sentido, eu não priorizei fazer atividade, cuidar da saúde, eu fiquei só no trabalho, trabalho, trabalho e hoje eu colho as consequências disso, aí hoje eu tento me reestruturar para que eu consiga administrar melhor esse tempo. (Patrícia)

Eu acho que o tempo, mas se a gente souber administrar direitinho a gente consegue fazer muita coisa. (Lara)

Os relatos referentes à conciliação do trabalho nas esferas pública e privada demonstram que de fato é uma dificuldade para a maioria das mulheres dividir-se em dois âmbitos, pois ambos exigem a realização de muitas tarefas e certificação de que tudo está sob controle.Em consonância com os achados de Zibetti e Pereira (2010), a concentração de muitas atividades majora a rotina das mulheres de modo que a rotina dividida entre demandas domésticas e profissionais lhes roubam horas de lazer ou descanso.

De domingo a domingo trabalhando, é muito trabalho, muita preocupação, muito problema [...] É difícil mas eu tento conciliar pra não ficar muito só trabalhando, mas é muito difícil, tem hora que o trabalho toma muito tempo mas eu tenho outras coisas também [...] (Eliete)

[...] toda mulher tem suas dificuldades. Então, faço meus trabalhos em casa, saio, venho pra escola, faço todo meu trabalho aqui, vou meio dia pra casa, tenho meus trabalhos em casa, como qualquer mulher, aí almoço, volto pra cá pra escola, tenho todo meu trabalho aqui e tenho todo meu trabalho em casa também. (Marina)

No entanto, em uma outra perspectiva, Jonathan (2011) afirma que a multiplicidade de papeis pode representar um fator favorável, que representa uma soma e não uma divisão, distanciando-se da condição de estresse supracitada. Tal vertente considera que as mulheres associam o acúmulo de funções e atividades ao sentimento de desafio e crescimento pessoal.

[...] é um desafio conciliar as demandas do universo profissional e as demandas do âmbito pessoal também e ao mesmo tempo você se manter em equilíbrio físico, um equilíbrio emocional para que você esteja bem consigo mesma. Então, mas eu entendo que eu sempre encaro desafios como algo positivo por que eu acho que eles contribuem para esse processo de desenvolvimento, de amadurecimento. (Ivana)

A dificuldade maior foi conciliar mesmo né, talvez ser mãe e ter a escola. [...] você se divide mais um pouco mas também você cresce muito, até como mãe mesmo, né... por que abre mais seus horizontes, você não fica somente ali dentro de casa... então você lida com outras pessoas, eu acho que isso me ajudou muito no meu crescimento pessoal. Ser empresária e ter uma escola né, então isso me ajudou bastante. (Maristela)

Recorrer à contratação de trabalhadoras domésticas foi considerado o mecanismo mais utilizado pelas mulheres, pois seis delas contam com empregadas para atender às demandas domésticas, três dispõem do apoio familiar e uma não utiliza nenhuma forma de apoio. Nas falas, é perceptível a noção de responsabilização pelo cuidado do lar, ainda que este seja partilhado no ambiente doméstico, principalmente no caso das mulheres casadas. Esse papel 
atribuído à mulher está tão enraizado que, até mesmo as mulheres que explicitam em suas falas não considerar diferenças entre homens e mulheres, atribuem a si próprias a responsabilidade de estar à frente dos afazes domésticos. Jablonski (2010) considera que os anos de socialização com distinções de gênero parecem ter consolidado, mesmo nas mulheres de alto nível de escolaridade, a noção de que as atividades domésticas não devem ou não precisam ser divididas igualitariamente.

Eu tenho uma pessoa que já está há alguns anos em nossa residência e é um apoio bem importante pra que eu consiga dar conta dessas coisas todas... (Ivana)

Olha, eu sempre, graças a Deus eu sempre tive funcionária na minha casa, pessoas boas que me ajudaram muito. São pessoas a quem eu delego e confio plenamente, que eu entrego minha casa, minhas coisas, até minha vida se precisar, tá ali dentro. (Cláudia)

Além do apoio de empregadas domésticas, foi identificada a utilização de apoio familiar por parte das mulheres, para conciliar demandas laborais e domésticas. O que se observa na fala delas é que a maior dificuldade na divisão de horas dedicadas ao trabalho e ao lar é o cuidado com os filhos. Nas falas abaixo, é demonstrada a terceirização do cuidado que, segundo Sorj (2013), representa uma tendência à divisão das atividades domésticas entre os cônjuges e o uso de artifícios externos, considerando que as mães, no contexto atual, não possuem grande disponibilidade de tempo dedicado à esfera privada, devido sua ascensão profissional.

Quando eu tive minha filha eu já trabalhava, ela sempre conviveu nesse universo da escola, então como eu sempre tive meus pais como suporte, eles cuidaram dela até um ano. (Patrícia)

\begin{abstract}
Engraçado, eu demorei um pouco pra colocar dois turnos, eu acho que foi esse medo mesmo de não dar conta. Assim, não é fácil não. Não é uma coisa simples, conciliar e você acaba também entregando um pouco a terceiros, né... acaba entregando um pouco assim à secretária do lar que a gente contratava na época [...] Eu tinha também minha irmã, ela me ajudava bastante. (Maristela)
\end{abstract}

Quanto à divisão de tarefas domésticas, os relatos demonstram que as mulheres, embora partilhem ou tentem partilhar as atividades entre os demais membros da família, a responsabilidade de controlar o espaço doméstico e as demandas familiares ainda é considerada da mulher. Santos e Casado (2011), inclusive, apontam novos rumos para as configurações de cuidado com o lar e desenvolvimento da carreira profissional, ao tratarem do fenômeno dual career families. $\mathrm{O}$ modelo, que aborda uma divisão igualitária de atividades, e considera a dupla carreira de homens e mulheres, é influenciado pelas projeções sociais e organizacionais. A fala de Marina traz uma tendência de mudança do posicionamento dos homens em relação às responsabilidades domésticas, que está se construindo através da perspectiva pós-moderna de rompimento de paradigmas.

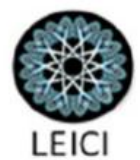


Eu tento dividir mas não é fácil, a juventude hoje ela é mais aceitável, eu tenho um filho de 20 anos que ele aceita, ele me ajuda mais. Já o meu marido que já é de uma outra geração, ele é mais resistente, então a gente sente a diferença. Os homens de antigamente eles acham que a responsabilidade é toda da mulher. (Marina)

A partilha da educação e cuidado com os filhos foi claramente demonstrada por Ivana, que afirma ser natural a divisão de tarefas relacionadas ao lar e às crianças. Vale ressaltar que esta empreendedora foi a única dentre as dez que não apresentou em sua fala distinções naturalizadas de gênero, isto é, ela demonstra compreensão dos papeis socialmente atribuídos: "[...] cada um, homem ou mulher, se constitui obviamente através das questões biológicas mas também se dá em função das experiências que eu vivo, das leituras que eu faço, das relações que eu estabeleço e aí é isso que vai determinando as diferenças" (Ivana).

[...] eu tenho essa possibilidade de compartilhar muito com meu esposo essa questão, até mesmo das atividades domésticas [...]E isso é feito com muita tranquilidade, não tem sofrimento não, por que não existe aquela questão de: "ah, tem que ser só você ou tem que ser só eu..." ele entende que eu tenho um trabalho e que demanda esforço, né... gosta, ele admira isso também e eu acho que na medida do possível tenta me ajudar, pra que as coisas funcionem bem, equipe né (risos). (Ivana)

Outra dificuldade registrada pelas mulheres no ambiente empresarial foi $o$ relacionamento interpessoal. Quando questionadas sobre as características que uma gestora competente deve possuir, as mulheres direcionaram suas falas para a habilidade de gerir conflitos e manter um bom relacionamento com as pessoas envolvidas nas atividades das escolas. Macedo et al. (2012) evidenciam em seus estudos que as mulheres apresentam problemas de relacionamento pessoal. Para elas, lidar com diferenças é um desafio, assim como foi demonstrado pelas falas seguintes.

Eu acredito que aqui na escola as dificuldades são bem pequenas por que todo mundo que trabalha com a gente se dedica, se doa e sempre busca o melhor pra escola, então aqui as dificuldades são mais relações interpessoais, por que em todo lugar acaba tendo né. (Lívia)

[...] lidar com gente, com o ser humano em vários âmbitos é muito difícil por que aqui eu lido com vários... o patrão aqui é o pai e a mãe, por que lidar com gente é muito difícil, lidar com pai de aluno, lidar com... cada um pensa de um jeito, cada um tem uma cabeça e procurar todos esses jeitos pra arrumar um jeito só é muito difícil [...] lidar com criança que também não é fácil, várias criações... (Eliete)

Muito embora as mulheres tenham demonstrado que possuem habilidades comunicativas para gerenciar conflitos, novamente, as mulheres julgam que apresentam "naturalmente" certas características mais apropriadas para uma boa gestão. Paralelamente, Franco (2014) detectou que a intuição, sensibilidade e flexibilidade no relacionamento interpessoal, estão presentes no estilo de gestão participativo, perceptíveis na postura feminina. Mais uma vez, é possível inferir que há um processo de naturalização que atribui à mulher facilidade de dialogar e escutar como extensões da sensibilidade, considerada própria

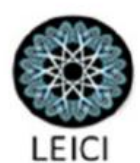


das mulheres. Nesse sentido, a facilidade de estabelecer relacionamentos interpessoais, segundo Gomes (2014), é de fato um valor socialmente atribuído às mulheres e é demonstrado pelas empreendedoras nas falas seguintes.

\begin{abstract}
Eu acho que é o 'estar perto do outro', assim... enquanto eu estou lá no pátio, eu tô recebendo os pais, isso de estar perto, de ser comunicativa, de conversar com todos os pais, de até sair do assunto escola, tem pais que me vêem como amiga, contam histórias... (Lara)

Essa capacidade de controlar, de amenizar os conflitos dentro da empresa, de você saber conversar, de você saber entender seu funcionário, de você saber desenvolver trabalhos em equipe (Marina)
\end{abstract}

Em suma, as empreendedoras demonstraram que os âmbitos laboral e doméstico possuem relação intrínseca. Assim como nos achados de Ferreira e Nogueira (2013), as dificuldades dos dois ambientes se misturam, de modo que os problemas de relacionamento surgem na organização atrelados ao lar. Vale ressaltar ainda que as mulheres associam características positivas e a identificação com a educação infantil à "essência feminina", de modo que apenas no posicionamento de Ivana, é perceptível a colocação de homens e mulheres de modo equiparado: como seres mutáveis, capacitados a desenvolver qualquer habilidade, passíveis de influências sociais e, portanto, sujeitos construídos socialmente.

\title{
5 Considerações Finais
}

Compreender as articulações dos ambientes doméstico e profissional, sob a perspectiva de gênero que as mulheres empreendedoras são influenciadas pressupõe o estudo do comportamento humano na civilização. Nesse sentido, o presente trabalho buscou analisar de que modo empreendedoras atuam como gestoras e conciliam demandas, no segmento de educação infantil, em Vitória da Conquista.

A análise do depoimento das empreendedoras subsidiou o entendimento das relações que se estabelecem entre os âmbitos doméstico e profissional. Desse modo, as decorrências da atuação feminina como gestora e mulher foram explanadas de modo a criticar os conceitos que estão enraizados socialmente. Nessa vertente, surge a importância de se estudar a forma como os conceitos construídos histórica e socialmente interferem na vida comum e nas diferentes conjecturas sociais. Referente à tal premissa, as entrevistadas revelaram que a atuação na educação infantil se deu por acreditarem possuir instinto maternal, sensibilidade e habilidade de percepção e ainda se posicionarem distintamente dos homens nessa perspectiva.

Assim como nos achados de Franco (2014), foi identificado um perfil de gestão feminino marcado por características como intuição, sensibilidade e flexibilidade de relacionamento. Muito embora esse perfil represente um padrão social feminino, cabe aqui questionar os parâmetros que foram impostos a essas mulheres para que elas adotassem esses comportamentos como algo que é esperado pela sociedade. Vale ressaltar ainda que as mulheres revelaram apresentar características ditas masculinas, para atender às demandas do cargo de gestão que ocupam e pela necessidade de serem líderes, firmes e racionais. Esse processo de significação, segundo Martins et al. (2010), se dá através do pressuposto de que

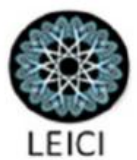


as mulheres são dóceis e emocionais, mas quando ocupam cargos de liderança, que são frequentemente associados à figura masculina, adotam características que a sociedade considera própria dos homens.

O perfil das empreendedoras analisadas corrobora com os estudos de Jonathan (2011), ao descrever uma postura pautada na autorrealização e crescimento pessoal, através do empreendedorismo, que oferece às mulheres a possibilidade de desenvolver seus próprios valores e crenças, exercer sua capacidade de decisão e sentir-se desafiadas constantemente, além do prazer que a atuação na gestão de escolas infantis proporciona. Dentre as principais dificuldades relacionadas ao cotidiano feminino, a multiplicidade de papeis, o estresse causado pela conciliação de demandas e a falta de tempo para realizar atividades foram consideradas dificuldades para as empreendedoras.

Nesse cenário de predeterminações relacionadas ao gênero, esta pesquisa mostra-se pertinente ao convidar para a reflexão sobre os estereótipos de masculinidade e feminilidade que estão, por vezes, estabelecidos na sociedade. Compreender os fenômenos sociais que cercam a realidade contemporânea e tendem a romper paradigmas estruturados histórico, social e culturalmente, portanto, torna-se uma necessidade de estudo e aprofundamento teórico-empírico. Quanto às limitações da pesquisa, ao se restringir à análise qualitativa, o estudo pode apresentar vieses de interpretação provenientes do pesquisador e/ou ocultação de posicionamentos por parte das empreendedoras.

Por fim, o presente estudo abre uma agenda de pesquisa, que inclui a investigação de áreas masculinizadas historicamente, tais como as engenharias e a tecnologia da informação. No que tange a necessidade de discussão do tema, vale ressaltar que a presença feminina nos ambientes organizacionais é crescente e, por isso, a compreensão das relações de gênero no âmbito profissional, principalmente em cargos de gestão, faz-se necessária para o entendimento multifacetado da Administração.

\section{Referências}

AIDAR, M. M. Empreendedorismo. São Paulo: Thomson Learning, 2007. 145 p. (Coleção Debates em Administração).

ALPERSTEDT, G. D.; FERREIRA, J. B.; SERAFIM, M. C. Empreendedorismo feminino: dificuldades vivenciadas em histórias de vida. In: ENCONTRO DE ESTUDOS EM EMPREENDEDORISMO E GESTÃO DE PEQUENAS EMPRESAS, 8, 2014, Goiânia. Anais...Goiania: ANEGEPE, 2014.

ALVES, V. P.; VIANA, H. B.; MORGAN, L.; LANDIM, A. Empreendedorismo feminino: uma análise do perfil de mulheres proprietárias de pequenas e médias empresas.

Observatorio de la Economía Latinoamericana, Brasil. Disponível em:<http://www.eumed.net/cursecon/ecolat/br/16/propietarias.html >.

BERGER, P. L.; LUCKMANN, T. A construção social da realidade. Petrópolis: Vozes, 2010. 32. ed. 239 p.

BERNARDI, L. A. Manual de empreendedorismo e gestão: fundamentos, estratégias e dinâmicas. São Paulo: Atlas, 2012.314 p.

COSTA; A. M. da; BARROS, D. F.; CARVALHO, J. L. F. A dimensão histórica dos discursos acerca do empreendedor e do empreendedorismo. In: ENCONTRO DA 
ASSOCIAÇÃO NACIONAL DOS PROGRAMAS DE PÓS-GRADUAÇÃO EM ADMINISTRAÇÃO, 35, 2011, Rio de Janeiro. Anais... Rio de Janeiro: ANPAD, 2011. CYRINO, R. Trabalho, temporalidade e representações sociais de gênero: uma análise da articulação entre trabalho doméstico e assalariado. Sociologias, Porto Alegre, v. 11, n. 21, jan./jun. 2009, p. 66-92.

DEDECCA, C. S.; RIBEIRO, C. S. M. de F.; ISHII, F. H. Gênero e jornada de trabalho: análise das relações entre mercado de trabalho e família. Trabalho, Educação e Saúde, Rio de Janeiro, v. 7 n. 1, p. 65-90. Mar./Jun. 2009.

FERREIRA, J. M.; NOGUEIRA, E. E. S. Mulheres e suas histórias: razão, sensibilidade e subjetividade no empreendedorismo feminino. RAC - Revista de Administração

Contemporânea, Rio de Janeiro, v. 17, n. 4, p. 398-417. Jul./Ago. 2013.

FILION, L. J. Visão e relações: elementos para um metamodelo empreendedor. RAE -

Revista de Administração de Empresas, v. 33, n. 6, nov.-dez, p.50-61, 1993.

Diferenças entre sistemas gerenciais de empreendedores e operadores de pequenos

negócios. RAE - Revista de Administração de Empresas, v. 39, n. 4, out-dez, 1999.

. Empreender: um sistema ecológico de vida. In: FILION, L. J.; DOLABELA, F. (Org).

Boa ideia! E agora? Plano de negócio, o caminho seguro para criar e gerenciar sua empresa.

São Paulo: Cultura Editores Associados. 2000. 352 p.

FONTELLES, M. J. et al. Metodologia da pesquisa científica: diretrizes para a elaboração de um protocolo de pesquisa. Revista Paraense de Medicina, v. 23, n. 3, p. 1-8, 2009.

Disponível em: <http://www.files.bvs.br/ upload/s/0101-5907/2009/v23n3/a1967.pdf.> Acesso em: 20 de agosto de 2017.

FRANCO, M. M. S. Empreendedorismo feminino: características empreendedoras das mulheres na gestão das micro e pequenas empresas. In: ENCONTRO DE ESTUDOS EM EMPREENDEDORISMO E GESTÃO DE PEQUENAS EMPRESAS, 8, 2014, Goiânia. Anais... Goiania: ANEGEPE, 2014.

GAUCHE, S.; VERDÚ, C. P.; SILVEIRA, A. A superação do conflito trabalho-família: naturalidade frente ao "bicho de sete cabeças". In: ENCONTRO DA ASSOCIAÇÃO NACIONAL DOS PROGRAMAS DE PÓS-GRADUAÇÃO EM ADMINISTRAÇÃO, 37, 2013, Rio de Janeiro. Anais... Rio de Janeiro: ANPAD, 2013.

GEM - GLOBAL ENTREPRENEURSHIP MONITOR. Empreendedorismo no Brasil: 2016. Curitiba: IBQP, 2017. Disponível em:

<http://www.sebrae.com.br/Sebrae/Portal\%20Sebrae/Anexos/gem\%20relat\%C3\%B3rio\%20e xecutivo\%202012.pdf>. Acesso em: 11 de agosto de 2017.

Empresômetro, 2017. Disponível em: <https://www.empresometro.com.br/> Acesso em: 02 de setembro de 2017.

GIL, A. C. Como elaborar projetos de pesquisa. 4. ed. São Paulo: Atlas, 2002. 175p.

Métodos e técnicas de pesquisa social. 6. ed. São Paulo: Atlas, 2008. 200p.

GUIMARÃES, M. da G. V.; PETEAN, E. B. L.; SOUZA, W. A. da R. de. Trabalho, família e estruturas de apoio: percepção de professoras universitárias de Manaus (AM). In:

ENCONTRO DA ASSOCIAÇÃO NACIONAL DOS PROGRAMAS DE PÓS-

GRADUAÇÃO EM ADMINISTRAÇÃO, 36, 2012, Rio de Janeiro. Anais... Rio de Janeiro: ANPAD, 2012.
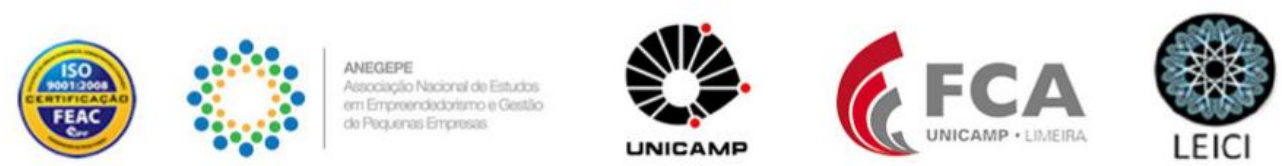
GOMES, A. F. O perfil empreendedor de mulheres que conduzem seu próprio negócio: um estudo na cidade de Vitória da Conquista-BA. Alcance - UNIVALI, v. 11, n.2 p. 207 - 226, Maio/Ago. 2004.

JABLONSKI, B. A divisão de tarefas domésticas entre homens e mulheres no cotidiano do casamento. Psicologia Ciência e Profissão, v. 30, n. 2, p. 262-275. 2010.

JONATHAN, E. G. Mulheres empreendedoras: medos, conquistas e qualidade de vida.

Psicologia em Estudo, Maringá, v. 10, n. 3, p. 373-382, set./dez. 2005.

Mulheres empreendedoras: o desafio da escolha do empreendedorismo e o exercício do poder. Psicologia Clínica, Rio de Janeiro, v. 23, n.1, p.65-85, 2011.

JULIEN, P. Empreendedorismo regional: e economia do conhecimento. São Paulo: Saraiva, 2010. 399 p.

LENZI, F. C.; SANTIAGO, N. M. A ação empreendedora. In: LENZI, F. C.; KIESEL, M. D.; ZUCCO, F. D. (Org). Ação empreendedora: como desenvolver e administrar o seu negócio com excelência. São Paulo: Gente. 2010. 379 p.

MACEDO, F. M. F.; BOAVA, D. L. T.; CAPPELLE, M. C. A.; OLIVEIRA, M. de L. S. Relações de gênero e subjetividade na mineração: um estudo a partir da fenomenologia social. RAC - Revista de Administração Contemporânea, v.16, n.2, art. 3, p. 217-236. Mar./Abr. 2012.

MACHADO, F. B. Dilemas de mulheres empreendedoras em empresas inovadoras nascentes. In: ENCONTRO DA ASSOCIAÇÃO NACIONAL DOS PROGRAMAS DE PÓSGRADUAÇÃO EM ADMINISTRAÇÃO, 36, 2012, Rio de Janeiro. Anais... Rio de Janeiro: ANPAD, 2012.

MACHADO, H. P. V.; GAZOLA, S.; ANEZ, M. E. M. Criação de empresas por mulheres: um estudo com empreendedoras em Natal, Rio Grande do Norte. RAM - Revista de Administração Mackenzie, v. 14, n. 5, p. 177-200. Out. 2013.

MARTINS, C. B.; CRNKOVIC, L. H.; PIZZINATTO, N. K.; MACCARI, E. A.

Empreendedorismo feminino: características e perfil de gestão em pequenas e médias empresas. Revista de Administração UFSM, Santa Maria, v. 3, n. 2, p. 288-302, mai./ago. 2010.

MELLO, S. C. B. de; CORDEIRO, A. T. Investigando novas articulações e possibilidades no discurso empreendedor: contexto, sujeito e ação. Organizações e Sociedades, Salvador, v.17 - n.53, p. 279-295, Abril/Junho, 2010.

OLIVEIRA, D. A.; BRANGION, A. R.; MAGALHÃES, Y. T. de. Representações sociais de gênero no setor de manutenção de uma empresa mineradora In: ENCONTRO DA ASSOCIAÇÃO NACIONAL DOS PROGRAMAS DE PÓS-GRADUAÇÃO EM ADMINISTRAÇÃO, 35, 2011, Rio de Janeiro. Anais... Rio de Janeiro: ANPAD, 2011. PELOGIO, E. A.; ROCHA, L. C. S.; MACHADO, H. V.; AÑEZ, M. E. M. Criação de empresas à luz do modelo de decisão effectuation: um estudo com mulheres empreendedoras no município de Currais Novos/RN. In: ENCONTRO DA ASSOCIAÇÃO NACIONAL DOS PROGRAMAS DE PÓS-GRADUAÇÃO EM ADMINISTRAÇÃO, 35, 2011, Rio de Janeiro. Anais... Rio de Janeiro: ANPAD, 2011.

PEREIRA, J. B. C.; ARAUJO, C. C. de; MIGUEL, J. G.; ALMEIDA, L. de O. S.; PALONI, L. M. A saliência de identidade de homens e mulheres do setor têxtil. In: ENCONTRO DA 
ASSOCIAÇÃO NACIONAL DOS PROGRAMAS DE PÓS-GRADUAÇÃO EM ADMINISTRAÇÃO, 38, 2014, Rio de Janeiro. Anais... Rio de Janeiro: ANPAD, 2014. SANTOS, H. B. dos; CASADO, T. O tradicional reconfigurado: a proposta de um modelo para casais de dupla carreira.In: ENCONTRO DA ASSOCIAÇÃO NACIONAL DOS PROGRAMAS DE PÓS-GRADUAÇÃO EM ADMINISTRAÇÃO, 35, 2011, Rio de Janeiro. Anais... Rio de Janeiro: ANPAD, 2011.

SALES, A. P. S.; FREITAS, R. C. de; MACEDO, S. B.; VILLARTA-NEDER, M. A. Tudo muda, mas nada muda?! O discurso sobre a imagem da mulher nas organizações. In:

ENCONTRO DA ASSOCIAÇÃO NACIONAL DOS PROGRAMAS DE PÓS-

GRADUAÇÃO EM ADMINISTRAÇÃO, 37, 2013, Rio de Janeiro. Anais... Rio de Janeiro: ANPAD, 2013.

SEBRAE - Serviço Brasileiro de Apoio às Micro e Pequenas Empresas. Pesquisa mulher empreendedora em MS. Campo Grande, 2014. Disponível em: <http://www.sebrae.com.br/Sebrae/Portal\%20Sebrae/UFs/MS/Anexos/Pesquisa\%20Empreen dedorismo\%20Feminino\%20no\%20MS.pdf> Acesso em: 12 de agosto de 2017.

SILVEIRA, D. T.; CÓRDOVA, F. P. A pesquisa científica. In: GERHARDT, T. E.; SILVEIRA, D. T. (Org.) Métodos de pesquisa. (Série educação à distância). Porto Alegre: Editora da UFRGS, 2009, 114 p.

SILVEIRA, N. S. P. da; HANASHIRO, D. M. M. Mulheres gerentes: a centralidade da maternidade na construção da identidade de gênero no trabalho. In: ENCONTRO DA ASSOCIAÇÃO NACIONAL DOS PROGRAMAS DE PÓS-GRADUAÇÃO EM ADMINISTRAÇÃO, 35, 2011, Rio de Janeiro. Anais... Rio de Janeiro: ANPAD, 2011. SORJ, B. Arenas de cuidado nas interseções entre gênero e classe social no Brasil. Cadernos de Pesquisa, v. 43, n.149, p. 478-491. Ago. 2013.

STROBINO, M. R. de C.; TEIXEIRA, R. M. Empreendedorismo feminino e o conflito trabalho-família: estudo de multicasos no setor de comércio de material de construção da cidade de Curitiba. Revista de Administração, São Paulo,v. 49, n. 1, p. 59-76. Mar. 2014. TOMAZ, R. Feminismo, maternidade e mídia: relações historicamente estreitas em revisão. Galaxia, São Paulo, n. 29, p. 155-166, jun. 2015.

VENTURA, M. M. O estudo de caso como modalidade de pesquisa. Revista SOCERJ Sociedade de Cardiologia do Estado do Rio de Janeiro, Rio de Janeiro, v. 20, n. 5, p. 383386, set./out. 2007.

ZANELLA, L. C. H. Metodologia de pesquisa. Florianópolis: Departamento de Ciências da Administração/UFSC. 2. ed. 2011. 134 p.

ZIBETTI, M. L. T.; PEREIRA, S. R. Mulheres e professoras: repercussões da dupla jornada nas condições de vida e no trabalho docente. Educar em Revista, Curitiba, Brasil, n. especial 2, p. 259-276, 2010. 